\title{
A syndrome of abnormal movements and dementia in leucotomized patients treated with phenothiazines
}

\author{
RICHARD HUNTER, C. J. EARL, AND DIETER JANZ \\ From the National Hospital, Queen Square, and Friern Hospital, London
}

In the course of a survey of a mental hospital population, patients were observed with abnormal movements, most marked in the face and tongue, and dementia, who at first sight presented a clinical picture of Huntington's chorea. All were found to have received prolonged treatment with chlorpromazine and/or other phenothiazine derivatives following prefrontal leucotomy. In none was there a history of encephalitis, nor was a family history of a similar disorder traced despite detailed enquiry.

We report in detail three cases and mention two others and discuss the relative importance of leucotomy and phenothiazines in the aetiology of this syndrome.

\section{MATERIAL}

CASE 1 E.C., a domestic, was born in 1895. She had no family history of mental or nervous disease. In 1941 she was admitted to a mental hospital with the diagnosis of manic-depressive psychosis and remained for three months and in 1945 was readmitted in relapse for a similar period. In 1947-9 came the third admission during which, in November 1948, a bilateral prefrontal leucotomy was performed. In 1950 she was admitted to Friern Hospital with the diagnosis of paraphrenia, and but for a short interval has been an in-patient there continuously since. On admission no abnormal physical signs were noted; mentally she was composed, but somewhat demented and disorientated in time and place, with recent and middle distance memory defect and a tendency to confabulate. In 1953, while on a tranquillizing regimen, at first with reserpine and later chlorpromazine (Largactil) in a dosage of $300 \mathrm{mg}$. with benzhexol (Artane), $10 \mathrm{mg}$. a day, she showed signs of Parkinsonism with pill-rolling movements and tremor of the hands. In 1960 abnormal movements of the face, particularly the mouth, and of the hands, were noted for the first time, and the following year they were stated definitely to be choreiform. In 1962 abnormal movements and repeated grunting noises were so marked that a confident diagnosis of Huntington's chorea was made. All drugs were withdrawn in February 1963.

In November 1963 she showed continuous abnormal movements of small amplitude of the choreiform type of the face, mouth, tongue, and hands. Most striking was the continous puffing and blowing out of her cheeks. She walked in a stiff-legged manner, her feet set rather widely apart and swaying slightly from side to side with each step. Mentally she was in fair contact and cooperative. Her manner and speech were childish and her intellectual functions severely reduced with a gross memory defect and disorientation in time and place. She had no recollection of the leucotomy operation and in fact strenuously denied it. In the ward she was reported to be clean and tidy but inert and could only be occupied for brief periods with simple tasks.

CASE 2 R.G., a housewife, was born in 1895. She had no family history of nervous or mental disorder. In 1943 she was admitted to Friern Hospital with the diagnosis of melancholia and treated with nine electroconvulsive shocks without improvement. In March 1947, a bilateral prefrontal leucotomy was performed. One month later she had an epileptic fit and she has continued to have fits at intervals since, including two episodes of status epilecticus. In 1955-8, while on a tranquillizing regimen, at first with chlorpromazine $300 \mathrm{mg}$. a day and later trifluoperazine (Stelazine) $20 \mathrm{mg}$. and benzhexolhydrochloride (Pipanol) $5 \mathrm{mg}$. a day, she developed a Parkinsonian syndrome with tremor and pill-rolling movements of the hands. In November 1958 she was described as being manneristic and 'a distressing case' because of her severe dementia and abnormal movements. In June 1961 it was noted that she continuously thrust out her tongue and gasped unintelligible answers. All drugs were withdrawn in September 1962.

In November 1963 her appearance was dramatic. She was large, friendly and cooperative within the narrow limits of her understanding. Her speech, which came in hoarse expiratory bursts, was almost incomprehensible, and accompanied by marked contortions of the face. Her voice was husky and she could not articulate consonants. There were continuous abnormal movements of the face, but the most striking feature was the rapid protrusion and withdrawal of the tongue (the so-called fly catcher tongue), while her lips were pouted and her breathing noisy. There were small abnormal movements of the upper limbs and more marked movements of the lower limbs. Her gait was widely based, her legs held stiffly while she walked 
with a swaying side-to-side movement with her arms abducted. She was severely demented and unable to give any account of herself or of her situation. In the ward she was reported to be inert and unable to perform the simplest task, and to need supervision even for washing and dressing.

CASE 3 L.S., a housewife, was born in 1909. An older sister had a short-lived depressive illness in her thirties, and her mother died aged 73 after three months in the geriatric ward of a mental hospital with a confusional state following a stroke, but without any previous history of breakdown, abnormal movements, or dementia. In 1951 she was admitted to a mental hospital for three months with a diagnosis of paranoid schizophrenia. In 1955-6 she was readmitted and treated with $\mathbf{4 0}$ insulin comas and 25 electroconvulsive shocks. In April 1956 bilateral prefrontal leucotomy was performed after which she was discharged. In 1958-62 she attended a psychiatric outpatient clinic with a diagnosis of chronic schizophrenia, and placed on a tranquillizing regimen with phenothiazine derivatives in the course of which she developed a Parkinsonian syndrome. In August 1962 abnormal movements, most marked in the face and hands, were first noted and attributed to the drugs she was receiving. In January 1963, as she was unable to care for herself, she was admitted to Friern Hospital. At this time all medication was withdrawn.

In November 1963 she showed mild choreiform movements in all four limbs with similar grimacing movements of the face, tongue and lower jaw, and dysarthria. She walked in a rather manneristic fashion with typical choreiform movements of her hands. Mentally she was in good contact and friendly. She had no insight and retained only fragmentary remnants of her once florid psychosis. Her memory for recent and middle distance events was severely impaired, and she showed a marked intellectual deficit of which she was partly aware, since her spontaneous complaints were 'my brain has been removed and I can't think and my arms keep moving'. In the ward she was clean with supervision, lacked initiative, and was unoccupied unless given specific commands.

\section{DISCUSSION}

The histories of three patients are presented who had been subjected to prefrontal leucotomy for a psychiatric illness and were later placed on a prolonged tranquillizing regimen with phenothiazine

1 derivatives. Subsequently they showed abnormal movements which in retrospect seem to have developed insidiously; these, coupled with their severe dementia gave them the appearance of suffering from Huntington's chorea. Cases 2 and 3 became incapable of maintaining themselves outside hospital because of personality and intellectual deterioration two and six years respectively after discharge following the operation, and the progressive dementia of case 2 can be traced in the hospital case notes.
Abnormal movements of the choreiform type we first noted 12, 11, and six years respectively after leucotomy but may have had an earlier and insidiow onset which escaped observation. In patients 1 and $\overline{\frac{\pi}{\sigma}}$ who were in long-stay wards, they may have been mistaken for the mannerisms and stereotypes of the chronic mental hospital patient, or for the transiegh side-effects of the phenothiazine derivatives which they were receiving, as happened in patient 3 wh was attending the out-patient department of psychiatric hospital when they were first observed:

DIFFERENTIAL DIAGNOSIS FROM HUNTINGTON: CHOREA It may be thought that these patients hact been initially misdiagnosed as suffering from $\overline{\bar{c}}$. psychosis whereas in fact they were suffering from Huntington's chorea with early but marked mental symptoms preceding the onset of abnormal move ments. This was the case in a patient recorded by Meyer and Beck (1954) who was subjected to leucor tomy for a mental illness presenting as an agitates depression with paranoid features but suspicious organic signs; later when he developed abnorma movements a positive family history of Hunting ton's chorea was obtained and he died six and a hajatb years after operation.

In none of our patients was a family histor $\mathbb{D}_{\vec{Q}} \overrightarrow{\mathrm{O}}$ Huntington's chorea elicited despite searching quiry. With the following two exceptions the parents of all died in their seventies without having showv mental or nervous symptoms. The father of ca? died aged 59 of bronchopneumonia, and the mo of case 3 died aged 73 in a mental hospital tore months after admission for a confusional state following a stroke. One of this patient's five sibs had a depressive illness in her thirties for which she was treated in a mental hospital, but she has re mained well for 15 years.

The age of onset of abnormal movements in our patients is also at variance with that of Huntington 8 chorea in which they commonly start in the fourtB decade (Kinnier Wilson, 1940). In our patients the developed in the sixth and seventh decades of life and in this respect they resemble more cases of senite. chorea following vascular accidents or othes lesions.

In our patients abnormal movements developeä. insidiously and were recognized only after they hag become established. Since then they have tended to remain circumscribed except in case 3 in which the are generalized, although, as in the other two cases they are most marked in the face. The dementia of cases 1 and 2 seems to have developed in the earlì years following leucotomy, judging from the case notes and the observation of nursing staff and relatives, and latterly to have remained stationary 
Such apparent halting of the pathological process is also unlike Huntington's chorea although the rate of progression may vary from time to time in the given case; and the average duration of the illness is about 15 years whereas our patients have been ill for 22,20 , and 12 years.

If then our cases differ both from Huntington's and so-called senile chorea, to what extent can their clinical features be attributed to the common factor all three share, namely, a preceding brain operation and prolonged treatment with phenothiazine derivatives?

THE ROLE OF LEUCOTOMY Disturbances of motor function are of course well known after leucotomy, particularly in cases where the cut has been made wittingly or unwittingly in a posterior plane. These include difficulties in swallowing and articulation, and the presence of a grasp and what has been called 'bull-dog' reflex (Freeman and Watts, 1950). In this connexion it is perhaps significant that our three patients were women, in whom a shorter anteriorposterior skull diameter may mislead the surgeon working from standard surface markings. However that may be, it is reasonable to assume on anatomical grounds that a motor disorder with abnormal movements could result as in our patients. Such an effect could be due to direct damage to the corpus striatum in the course of the operation, since the head of caudate nucleus lies in the plane of any cut posterior to the most anterior plane of operation indicated in Figures 8 and 9 of Meyer and Beck (1954), and there is now general agreement about the importance of striatal lesions in the genesis of abnormal movements as in Huntington's chorea (Denny-Brown, 1962). In fact pneumoencephalography in case 3 revealed the frontal horn enlargement with atrophy of the head of the caudate nucleus characteristic of this condition.

Besides direct damage it is also possible that a degenerative process consequent upon the cutting of fibre tracts may be responsible. Such an explanation would serve to account for the interval of years between the operation and the onset of abnormal movements, which might otherwise be thought to indicate that they were unrelated. The possible effect of drugs apart, which will be considered later, there is evidence that the operation initiates a progressive neuronal degeneration which extends transsynaptically. The severity and extent of this degeneration appears to be directly proportional to the size of the original lesion and to the duration of survival (Meyer and Beck, 1954; Beck, 1963, personal communication). That the operation initiates such a degenerative process is also in keeping with clinical experience that post-leucotomy deficits may become increasingly severe and hence more obvious with the passage of time. It is perhaps for this reason that earlier enthusiastic reports of leucotomy results later had to be modified in face of the ever increasing numbers of operated subjects becoming mental, physical, or social cripples (Smith, 1963). It is noteworthy that at the time of writing such cases make up approximately $7 \%$ of the chronic population of the hospital in which the patients reported here reside.

It is well recognized that involuntary movements may appear after an interval following head injury. Through the courtesy of Dr. R. A. Henson we have seen a patient who showed similar abnormal movements following subdural haematoma as case 2 . We know of a fourth patient subjected to two leucotomy operations for a predominantly obsessive-compulsive disorder who 11 years later showed the syndrome we describe, but unfortunately she was not available for inclusion in this study. She was addicted to barbiturates and has also developed a Parkinsonian syndrome during treatment with phenothiazines. A fifth patient leucotomized in 1950 and treated with phenothiazines from 1956-8 but in irregular dosage and without developing Parkinsonism, now shows the same features as case 3 but her predominant mood of intense hostility made investigation impossible. In addition, minor abnormal movements were seen in $8 \%$ of 140 leucotomized patients recently surveyed in Friern Hospital.

THE ROLE OF PHENOTHIAZINES The question remains whether and to what extent the administration of phenothiazine derivatives was responsible for the picture presented by our patients.

Two main groups of neurological complications due to these drugs have been described: 1, a hypokinetic Parkinsonian syndrome and 2, a hyperkinetic syndrome consisting either of slow movements such as oculogyric crises, torticollis and opisthotonus, or rapid bizarre choreiform movements affecting particularly the lips, jaws, tongue, pharynx, and neck musculature (Kulenkampff and Tarnow, 1956); the arms may also be involved (Freyhan, 1957) and more rarely the legs (Hartmann and Hippius, 1959). The first, the Parkinsonian syndrome, is usually of gradual onset and depends on dosage and duration of treatment; it may become-less conspicuous with time, reduction of dose, or concurrent administration of anti-Parkinsonian drugs, and is claimed to be reversible when phenothiazines are stopped. The second, which Delay, Deniker, Green, and Mordret (1957) have called the 'excito-motor syndrome', has been observed only as an acute and dramatic, but transitory and harmless complication occurring soon after phenothiazine treatnent is initiated (Meyler, 
1963), with the exception of the reports of Sigwald, Bouttier, and Courvoisier (1959a) and Sigwald, Bouttier, Raymondeaud. and Piot (1959b) and Uhrbrand and Faurbye in 1960.

Sigwald et al. (1959a), in a paper on the neurological complications of neuroleptic drugs, mention that ' $a$ dyskinetic syndrome of the face, mouth, tongue, and jaw musculature' such as is seen in acute phenothiazine intoxication, may very rarely occur as a persistent complication of prolonged phenothiazine medication. They were unable to find any other reports of such cases in the literature. Their four patients were described in more detail in another paper (Sigwald et al., 1959b). One had trigeminal and another post-herpetic neuralgia, the third an anxiety state, and the fourth an obsessional illness. All four were women, as were our patients, and like ours they belonged to the older age groups ranging from 54 to 69 years. They had been on phenothiazines for periods varying from eight to 18 months with a minimum dose of chlorpromazine of $75 \mathrm{mg}$. a day; other phenothiazine derivatives given to their patients were prochlorperazine (Stemetil), laevomepromazine (Nozinan), and one patient also received reserpine. Despite withdrawal of medication abnormal movements had persisted though in diminished form and without troubling the patients for a follow-up period varying from six to 27 months at the time of writing.

Uhrbrand and Faurbye's (1960) cases of what they call 'bucco-linguo-masticatory dyskinesia' are in many ways similar to our own. In particular they point out that most cases of the persistent type followed prolonged treatment with phenothiazines (in their series most commonly following chlorpromazine, perphenazine, and thioridazine) whereas the reversible dyskinetic syndromes described in the literature occurred at an early stage of treatment. They also draw attention to the fact that the persistent dyskinetic syndrome occurred mostly in elderly patients and in younger patients with organic brain disease. Among the elderly too there was a high incidence of recognized organic brain disease, mostly dementia in association with cerebrovascular disease. In three of their persistent cases there was a history of leucotomy following electroconvulsive treatment; in three others they consider electroconvulsive treatment alone was sufficient 'organic' factor.

That such complications due to phenothiazines should persist is perhaps not surprising if it is remembered that they interfere directly with cerebral metabolism (Himwich, 1960), and indeed have been shown potentially to cause structural changes in the basal nuclei (Roizin, True, and Knight, 1959; Grünthal and Walther-Büel, 1960). It is also reason- able to assume that neurological complications should occur more frequently and be more marked in patients who have established brain damage or $\mathbb{D}$ disease, whether circumscribed or diffuse. This has indeed frequently been observed and remarked upon $\stackrel{\text { ? }}{\subseteq}$ clinically (Helmchen, 1963; Helmchen and Hippius, $\widehat{\widehat{C}}$ 1962; Myrianthopoulos, Kurland, and Kurland, ${ }_{0}$ 1962; Veltin, 1960). This is in keeping with general experience that phenothiazine derivatives may induce $\frac{\overline{\mathrm{T}}}{\mathrm{v}}$ fits in patients with brain damage and increase the frequency of fits in established epileptics (Hollister, 1961). By the same token, if the evidence is accepted that phenothiazine derivatives may cause permanento neurological damage, it seems likely that this shouldo occur earlier and be more marked in patients with $\overline{\overline{0}}$. pre-existing disease of the brain who are known to be $\mathbb{Q}$ more prone to develop toxic reactions to these drugs. I Indeed through the courtesy of Dr. Macdonald ${ }^{\text {s }}$ Critchley we have seen another elderly woman. believed to be suffering from cerebrovascular disease $\overrightarrow{.}$ in whom a similar persistent face-tongue syndrome ${ }_{\sigma}^{\omega}$ followed a few months' treatment with perphenazine (Fentazin).

PHENOTHIAZINES AND LEUCOTOMY In our threect patients distressing abnormal movements have pe्tiv sisted for more than 12 months after cessation of $\overrightarrow{0}$ phenothiazine medication and show no signs \& $\mathrm{g}$ 을 diminishing, and in the two other patients mentionedpassim they have persisted unchanged for three and $\subseteq$ six years respectively. All had received phen $8-\bar{D}$ thiazines continuously for a period of years as is now $\vec{c}$ the fashion. Four had developed a Parkinsonion syndrome which was treated by reduction of dose and concurrent administration of anti-Parkinsoniano agents. Only later did they almost imperceptibly develop the syndrome described here. In all the braino was damaged by leucotomy, an operation which, as has been shown, may involve the striatum, a struc- $\stackrel{\mathbb{Q}}{\circ}$ ture on which phenothiazines act chemically, as the $\overrightarrow{\vec{O}}$ clinical evidence of the common transitory toxic 3 manifestations described above indicates.

If this pathological explanation of our clinicalo findings is correct and the damaged brain is more vulnerable to phenothiazine poisoning, it may not be without significance that all our patients, in addition: to leucotomy, had at some stage received electroconvulsive shocks and one also a course of insulin comas.

It appears therefore that in our cases the dementiao was the consequence of leucotomy, while the persistent abnormal movements were due to pro-o longed treatment with phenothiazines producing chronic intoxication and possibly further structuralos changes in a brain in which a degenerative process $N$ had already been initiated surgically.

.

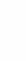




\section{CONCLUSIONS}

A distressing syndrome of persistent abnormal movements predominantly affecting the face, tongue and jaw, combined with severe dementia, may be produced in patients who for psychiatric reasons have been submitted to leucotomy and prolonged treatment with phenothiazine derivatives. This syndrome may be mistaken for Huntington's or senile chorea. So far all the patients we have observed were women past middle age.

It appears that prolonged treatment with phenothiazines even in moderate doses may be more hazardous than has been thought and produce irreversible neurological damage, particularly in older patients with brain damage.

\section{SUMMARY}

Three patients are described in detail and two others referred to who developed an apparently irreversible syndrome of abnormal movements of a distressing kind associated with dementia. They were at first mistakenly thought to be suffering from Huntington's chorea. All had a negative family history but had been subjected to prefrontal leucotomy and prolonged medication with phenothiazine derivatives. The differential diagnosis and relative significance of these factors are discussed.

\section{REFERENCES}

Delay, J., Deniker, P., Green, A., and Mordret, M. (1957). Presse méd. 65, 1771.

Denny-Brown, D. (1962). The Basal Ganglia and their Relation to the Disorders of Movement. Oxford University Press, London.

Freeman, W., and Watts, J. W. (1950). Psychosurgery, 2nd ed. Thomas, Springfield, Illinois.

Freyhan, F. A. (1957). Nervenarzt, 28, 504.

Grünthal, E., and Walther-Büel, H. (1960). Psychiat. et Neurol. (Basel), 140, 249.

Hartmann, K., and Hippius, H. (1959). Arztl. Wschr., 14, 307.

Helmchen, H. (1963). Fortschr. Neurol. Psychiat, 31, 160.

edited by $\mathbf{H}$. Kranz and K. Heinrich. Thieme, Stuttgart.

Himwich, H. E. (1960). In Drugs and Behaviour, edited by L. Uhr and J. G. Miller, pp. 41-85. Wiley, New York.

Hollister, L. E. (1961). New Engl. J. Med., 264, 291.

Kulenkampff, C., and Tarnow, G. (1956). Nervenarzt, 27, 178.

Meyer, A., and Beck, E. (1954). Prefrontal Leucotomy and Related Operations. Oliver and Boyd, Edinburgh.

Meyler, L. (1963). Side Effects of Drugs, 4th ed., Excerpta Medica Foundation, Amsterdam.

Myrianthopoulos, N. C., Kurland, A. A., and Kurland, L. T. (1962). Arch. Neurol. Psychiat. (Chicago), 6, 5.

Roizin, L. True, C., and Knight, M. (1959). In The Effect of Pharma. cologic Agents on the Nervous System, edited by F. J. Braceland. Ass. Res. nerv. ment. Dis., 37, 285.

Sigwald, J., Bouttier, D., and Courvoisier, S. (1959a). Rev. Neurol., $100,553$. 751 .

Smith, A. (1963), Lancet, 1, 495.

Uhrbrand, L., and Faurbye, A. (1960). Psychopharmacologia (Berl.), 1, 408.

Veltin, A. (1960). Med. exp. (Basel), $2,141$.

Wilson, S. A. Kinnier (1940). Neurology, edited by A. N. Bruce, vol. 2. Arnold, London. 